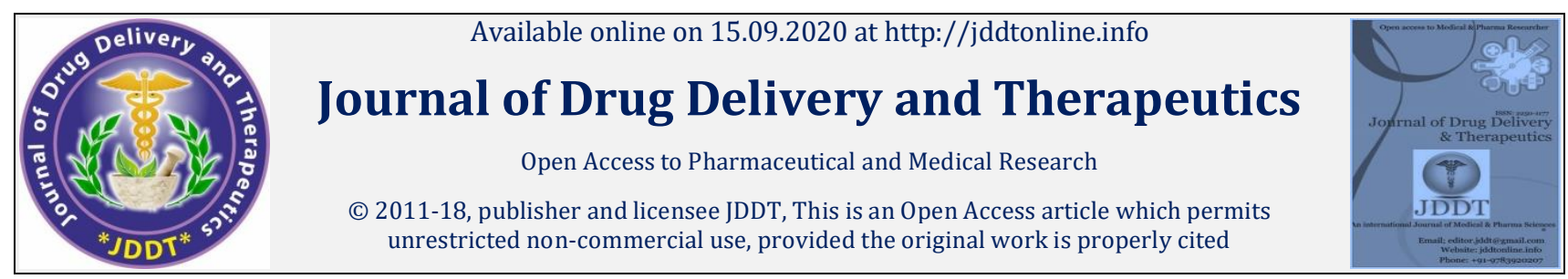

Open $\odot$ Access

Research Article

\title{
Effect of Curcuma longa Aqueous Extract on Male Fertility in Aluminum Exposed Wistar Rats
}

\author{
Farouk BOUDOU ${ }^{1,2, *}$, Malika BENDAHMANE-SALMI1,2, Mokhtar BENABDERRAHMANE1 , Amal BELAKREDAR¹, \\ Abdelkrim BENALIA ${ }^{2}$, Benali BEGHDADLI², AND Bader dine Abdelkrim KANDOUCI ${ }^{2}$
}

1. Department of Biology, Faculty of Natural and Life Sciences, DjillaliLiabes University of Sidi-Bel-Abbes, Sidi-Bel-Abbes, Algeria

2. Research Laboratory of Environment and Health (RLEH), Faculty of Medicine, Sidi-Bel-Abbes, Algeria

\begin{abstract}
To assess the effects of Curcuma longa aqueous extract (CE) on fertility in male rats exposed to Aluminum chloride (AlCl3), Twenty four male rats, 3 months old, divided into 4 groups $(n=6)$ were used. Animal from the first group received, by the oral route, water-containing AlCl3 at the dose of $34 \mathrm{mg} / \mathrm{kg}$ body weight (BW). Rats from the second group received both AlCl3 at the same dose in combination with oral treatment of CE at a dose of $200 \mathrm{mg} / \mathrm{kg}$ BW. The third group received only an oral administration of CE with the same dose. Rats from the four th group, without any treatment, served as control. After 4 weeks of experimentation, AlCl3 exposure showed a significant decrease in sperm concentration ( $4.58 \pm 0.65 \times 106$ cells $/ \mathrm{ml})$, and percentage of viability $(61.53 \pm 23.63 \%)$, and an increase of morphological abnormalities $(26.11 \pm 17.84 \%)$. A significant decreased in serum testosterone levels $(0.31 \pm 0.26 \mathrm{ng} / \mathrm{ml})$ and an increase of testicular malondialdehyde (MDA) level $(0.16 \pm 0.015$ $\mu \mathrm{M} / \mathrm{g}$ ) were also observed. Histological examination of the testes showed degeneration of the seminiferous tubules, germ line cells, and interstitial cells. However, CE treatment concomitant to AlCl3 showed that the rate of morphological abnormalities $(19 \pm 2.65 \%)$ is significantly decreased compared to $\mathrm{AlCl} 3$ group, with a significant increase in serum testosterone $(1.17 \pm 0.24 \mathrm{ng} / \mathrm{ml})$ and a significant decrease in MDA $(0.11 \pm 0.003 \mu \mathrm{M} / \mathrm{g})$ level. Microscopic examination revealed a significant regeneration of seminiferous tubules and interstitial cells. This study demonstrated an ameliorative effect of Curcuma longa aqueous extract in testicular tissue and sperm quality.
\end{abstract}

Keywords: Curcuma longa, Aluminum, fertility, testosterone, malondialdehyde (MDA), sperm.

Article Info: Received 09 July 2020; Review Completed 12 August 2020; Accepted 19 August 2020; Available online 15 September 2020

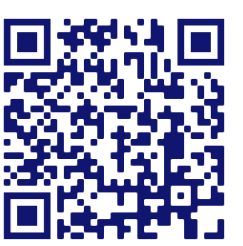

Cite this article as:

Boudou F, Bendahmane-Salmi M, Benabderrahmane M, Belakredar A, Benalia A, Beghdadli B, Kandouci BDA, Effect of Curcuma longa Aqueous Extract on Male Fertility in Aluminum Exposed Wistar Rats , Journal of Drug Delivery and Therapeutics. 2020; 10(5):11-17 http://dx.doi.org/10.22270/jddt.v10i5.4275

*Address for Correspondence:

Farouk BOUDOU, Department of Biology, Faculty of Natural and Life Sciences, DjillaliLiabes University of Sidi-Bel-Abbes, Sidi-Bel-Abbes, Algeria

\section{INTRODUCTION}

Aluminum (Al) is an abundant element in the earth's crust and is widely dispersed throughout the environment. Nowadays, aluminum salts are included in cosmetics, food processing, and storage and also used in various nonprescription drugs ${ }^{1}$. It has for a long time been considered on an indifferent element from a toxicological point of view. However, it is unclear whether the normal environmental levels of Al. Aluminum is known as a neurotoxin that can cause certain diseases such as Alzheimer's disease, dialysis dementia, Parkinsonism, and amyotrophic lateral sclerosis ${ }^{2}$. In addition to its neurotoxicity, $\mathrm{Al}$ affects other body structures like the skeletal system ${ }^{3}$, brain tissue, bone, blood cells, liver and kidney 3,4 . The sources of Al are especially corn, yellow cheese, salt, herbs, spices, tea, cosmetics, aluminum ware, and containers. Also, $\mathrm{Al}$ is widely used in antacid drugs, as well as in food additives and toothpaste 1. Environmental pollution with the different aluminum- containing compounds, especially those in industrial wastewater, exposes people to higher than normal levels of $\mathrm{Al}^{5}$. Aluminum ingestion in excessive amount leads to accumulation in target organs and has been associated with damage of testicular tissues of both humans and animals, with alteration in the histology of testis 6,7 deterioration in spermatogenesis and sperm quality; enhancement of free radicals and alterations in antioxidant enzymes ${ }^{8,} 9,10$ interruptions in sex hormone secretion 11,12 and biochemical changes in the testis and other accessory reproductive organs $^{13,14}$ are some of the aspects suggested that $\mathrm{Al}$ exposure harms the reproduction male function. Furthermore, the use of medicinal plants is a great contribution to treat primary medical problems. A variety of plants are claimed to have fertility regulating properties ${ }^{15}$. One of these plants is Curcuma longa. It's belonging to the Zingiberaceae family and has been widely used as a medicine, condiment, and cosmetics worldwide and valued 
as a functional food because of its health-promoting potentials. The rhizome of $C$. longa, a traditional medicine used for centuries in the Indian subcontinent, has been scientifically validated for its antioxidant, antimicrobial, antiarthritic, anticancer, carminative, stomachic, tonic, analgesic, hemostatic and anti-inflammatory activities ${ }^{16}$. The beneficial properties of $C$. longa have been associated with antioxidant activity 17, 18. And most of the studies performed on C. longa focused on curcuminoid components which comprised curcumin, dimethoxycurcumin, and bisdemethoxycurcumin ${ }^{19}$. The most important feature of curcumin is that it has no side effects despite being a therapeutic agent with multiple beneficial functions. It acts as a scavenger of free radicals ${ }^{20}$. Curcumin is considered to be an effective antioxidant against oxidative tissue damage. It can significantly inhibit the generation of reactive oxygen species (ROS) both in vitro and in vivo 21 . Based on the bibliographic database, our research work tends to assess the beneficial effects of Curcuma longa aqueous extract on Aluminum chloride-induced damages in the testis of adult male rats.

\section{MATERIALS AND METHODS}

\section{Preparation of Curcuma longa aqueous extract (CE)}

$25 \mathrm{~g}$ of the powder is boiled in $250 \mathrm{~mL}\left(100^{\circ} \mathrm{C}\right)$ water bath reflux system for $15 \mathrm{~min}$ and then filtered with $\mathrm{N}^{\circ} 1$ Whatman Millipore filter paper. The filtrate is combined, centrifuged at $4000 \mathrm{rpm}$ for $20 \mathrm{~min}$, the supernatant is concentrated to dryness using a rotary evaporator and the residue is stored at $4^{\circ} \mathrm{C}$ until use. This procedure was repeated weekly throughout the study 22 .

\section{Animals and experimental design}

Experiments were carried out on 24 albino mature males, aged 3 months and weighing $193.9 \pm 26.46 \mathrm{~g}$. The animals were housed in a room with a 12/12-hour light/ dark cycle, at $22 \pm 2{ }^{\circ} \mathrm{C}$, and had access to ad libitum to water and special rodent pellet diet $(15 \%$ proteins). Rats were randomly allocated into 4 groups, with 6 rats in each group. The 4 groups were: $\mathrm{AlCl}_{3}$ group, received $1 / 25 \mathrm{LD}_{50}$ of Aluminum chloride at a dose of $34 \mathrm{mg} / \mathrm{kg} \mathrm{BW}^{23}$; $\mathrm{Al}+\mathrm{CE}$ group receiving orally both $\mathrm{AlCl}_{3}$ at the same dose and $1 / 25 \mathrm{LD}_{50}$ of $\mathrm{CE}$ at a dose of $200 \mathrm{mg} / \mathrm{kg} \mathrm{BW}^{24}$; the third group received only CE at the same dose and route as the previous group; and control group (CONT) without any treatment. All the experiments lasted for 30 days.

\section{Biological samples collection}

At the end of the experiment, the animals were sacrificed in the morning after fasting for 12 hours and anesthetizing with diethyl ether in a large desiccator ${ }^{25}$. After incision of the abdomen, blood is collected from the inferior cava vena for the determination of testosterone level by using immunoassay commercial kits (VIDAS Assays, BIOMERIEUX). The testicles are carefully removed, separated from their epididymis, and rinsed with cold saline solution. The right ones were used for histological study according to standard techniques, after fixation in fixative solution (formalin 1/10), paraffin embedding, and staining with hematoxylin-eosin ${ }^{15}$. While the left ones are used to prepare tissue homogenate, by grinding $1 \mathrm{~g}$ of testis in $5 \mathrm{~mL}$ of $0.01 \mathrm{M}$ phosphate buffer
$\mathrm{pH} 7.4$ at $4^{\circ} \mathrm{C}$, and centrifuged at $3000 \mathrm{rpm}$ for $10 \mathrm{~min}$. The supernatant was kept frozen $\left(-20^{\circ} \mathrm{C}\right)$ to be used for the ulterior determination of malondialdehyde (MDA) level as described by Azad et al., (2019)26. The epididymis of each rat was placed in a petri dish, cut with scissors, and homogenized in $1 \mathrm{~mL}$ of physiological saline solution $(0.9 \%)$ at $35-37{ }^{\circ} \mathrm{C}$ for $15 \mathrm{~min}$ to form the sperm suspension. Semen characteristics, including sperm count, percent viability, and sperm morphology, were evaluated according to Wang, $(2002)^{27}$.

\section{Statistical Analysis}

Results were represented as mean \pm SD. The data were analyzed by using one-way analysis of variance (ANOVA) followed by the Bonferroni t-test using SigmaPlot version 11.0. $P$ values $<0.05$ were considered significant.

\section{RESULTS}

Table 1 shows that all semen parameters of the $\mathrm{AlCl} 3$ exposed group were significantly affected compared to the other experimental groups. A significant decreased in sperm count, percent viability, and an increase in sperm abnormal morphology were showed in the $\mathrm{AlCl} 3$ group compared to control. However, a significant improvement was observed in the sperm morphology of the animals belonging to the $\mathrm{AlCl} 3+\mathrm{CE}$ group comparatively to the group of rats exposed to only AlCl3. But, no significant changes were observed in sperm count and percentage of viability between these two groups. For the Hormonal assay, the results showed that the administration of $\mathrm{AlCl} 3$ significantly decreased serum testosterone levels $(0.31 \pm 0.26 \mathrm{ng} / \mathrm{ml})$ as compared with the other experimental groups. Curcuma longa treatment showed a very significant increase in serum testosterone of the CE group $(3.16 \pm 3.05 \mathrm{ng} / \mathrm{ml})$ and an important improvement in this hormone level in the $\mathrm{Al}+\mathrm{CE}$ group $(1.17 \pm 0.24 \mathrm{ng} / \mathrm{ml})$ (Figure 1). Figure 2 showed that AlCl3administration for 30 days significantly increased the MDA level $(0.16 \pm 0.015 \mu \mathrm{M} / \mathrm{g})$ as compared to the controls $(0.14 \pm 0.002 \mu \mathrm{M} / \mathrm{g})$. On the contrary, $\mathrm{AlCl} 3$ concomitant with Curcuma longa treatment led to a significant reduction in MDA level $(0.11 \pm 0.003 \mu \mathrm{M} / \mathrm{g})$ Histological study in the testicles reveals a normal architecture in control and CE groups (Figures 3 and 6) showing seminiferous tubules richly populated with a healthy appearance. All stages of the spermatogenic lines cells such as spermatogonia, spermatocyte, spermatids, and spermatozoa, even Sertoli cells could be identified in the seminiferous tubules. Lumen could easily be delineated in almost all the tubules and the majority of them were filled by mature spermatozoa. While the observation of histological sections of the AlCl3exposed group (Figure 4) shows that all these stages are affected. Among the disturbances reported: degeneration of the seminiferous tubules, a total absence of sperm and/or a low sperm count, with large interstitial spaces and lack of Lydig cells around basement membranes. However, Curcuma longa administration to rats concomitantly exposed to AlCl3 (Figure 5), shows a significant regeneration of the majority of seminiferous tubules structure and interstitial cells, with a good development of the spermatogenesis indicated by sperm-filled lumens of seminiferous tubes. 
Table 1: Semen parameters of the different experimental groups

\begin{tabular}{|c|c|c|c|c|}
\hline \multirow{2}{*}{ Parameters } & \multicolumn{3}{|c|}{ Groups } \\
\cline { 2 - 5 } & $\mathrm{AlCl}_{3}$ & $\mathrm{AlCl}_{3}+\mathbf{C E}$ & CE & \multicolumn{1}{|c|}{ CONT } \\
\hline Sperm count (106/ml) & $4.58 \pm 0.65^{\mathbf{a}}$ & $5.80 \pm 0.56^{\mathbf{a}}$ & $9.30 \pm 0.35^{\mathbf{b}}$ & $11.52 \pm 0.77^{\mathbf{b}}$ \\
\hline Morphology (abnormal \%) & $26.11 \pm 17.84^{\mathbf{a}}$ & $19 \pm 2.65^{\mathbf{b}}$ & $21 \pm 1.00^{\mathbf{b}}$ & $16.67 \pm 1.53^{\mathbf{b}}$ \\
\hline Viability (\%) & $61.53 \pm 23.60^{\mathbf{a}}$ & $67.33 \pm 5.03^{\mathbf{a}}$ & $66.67 \pm 4.93^{\mathbf{b}}$ & $76.33 \pm 6.51^{\mathbf{c}}$ \\
\hline
\end{tabular}

$\mathrm{AlCl}_{3}$ : Aluminum chloride exposed group; $\mathrm{AlCl}_{3}+\mathrm{CE}$ : $\mathrm{Al}$ and Curcuma longa aqueous extract exposed group; CE: Only C. longa aqueous extract-treated group; CONT: a control group with no treatment. Data are expressed as means \pm SD ( $n=6)$. A comparison between groups was made using the Bonferroni t-test. Column not sharing a common letter (a-c) differ significantly at $\mathrm{p}<0.05$ (Bonferroni t-test).

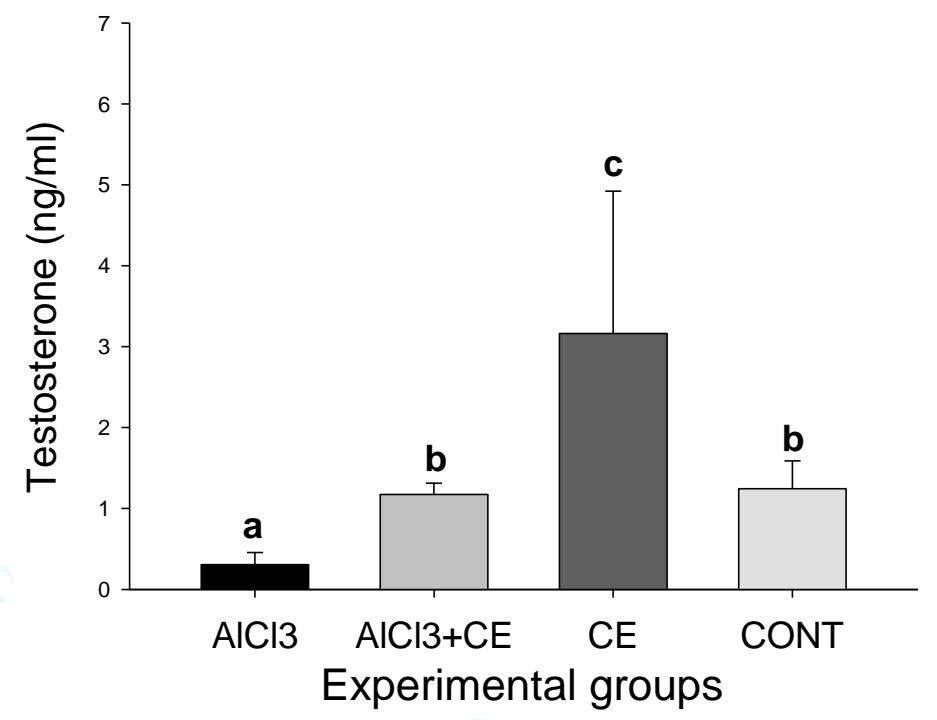

Figure 1: Evaluation of Testosterone level in different experimental groups. $\mathrm{AlCl}_{3}$ : Aluminum chloride exposed group; $\mathrm{AlCl}_{3}+\mathrm{CE}$ : Al and Curcuma longa aqueous extract exposed group; CE: Only $\mathrm{C}$. longa aqueous extract-treated group; CONT: a control group with no treatment. Data are expressed as means \pm SD $(n=6)$. A comparison between groups was made using the Bonferroni $t$-test. Column not sharing a common letter (a-c) differ significantly at $p<0.05$ (Bonferroni t-test).

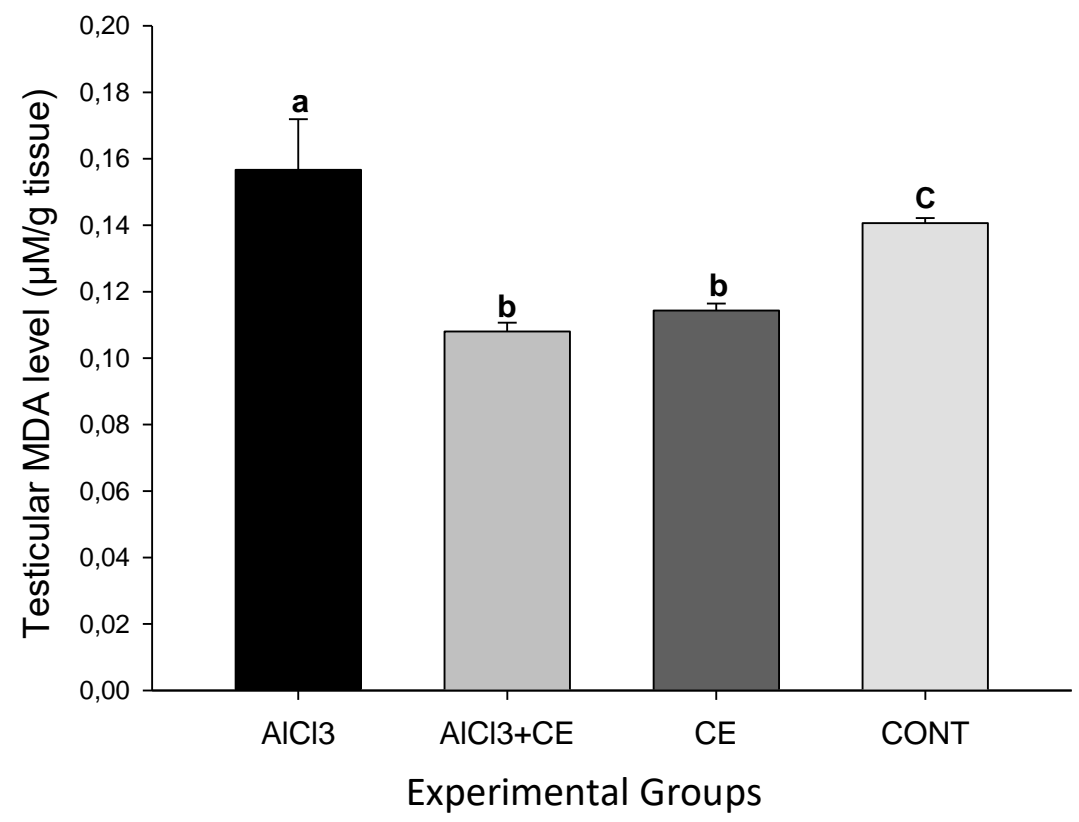

Figure 2: Evaluation of Testicular Manoldyaldhyde (MDA) levels in different experimental groups. AlCl3: Aluminum chloride exposed group; $\mathrm{AlCl} 3+\mathrm{CE}$ : $\mathrm{Al}$ and Curcuma longa aqueous extract exposed group; CE: Only $C$. longa aqueous extract-treated group; CONT: a control group with no treatment. Data are expressed as means \pm SD $(n=6)$. A comparison between groups was made using the Bonferroni t-test. Column not sharing a common letter (a-c) differ significantly at $\mathbf{p}<0.05$ (Bonferroni t-test). 


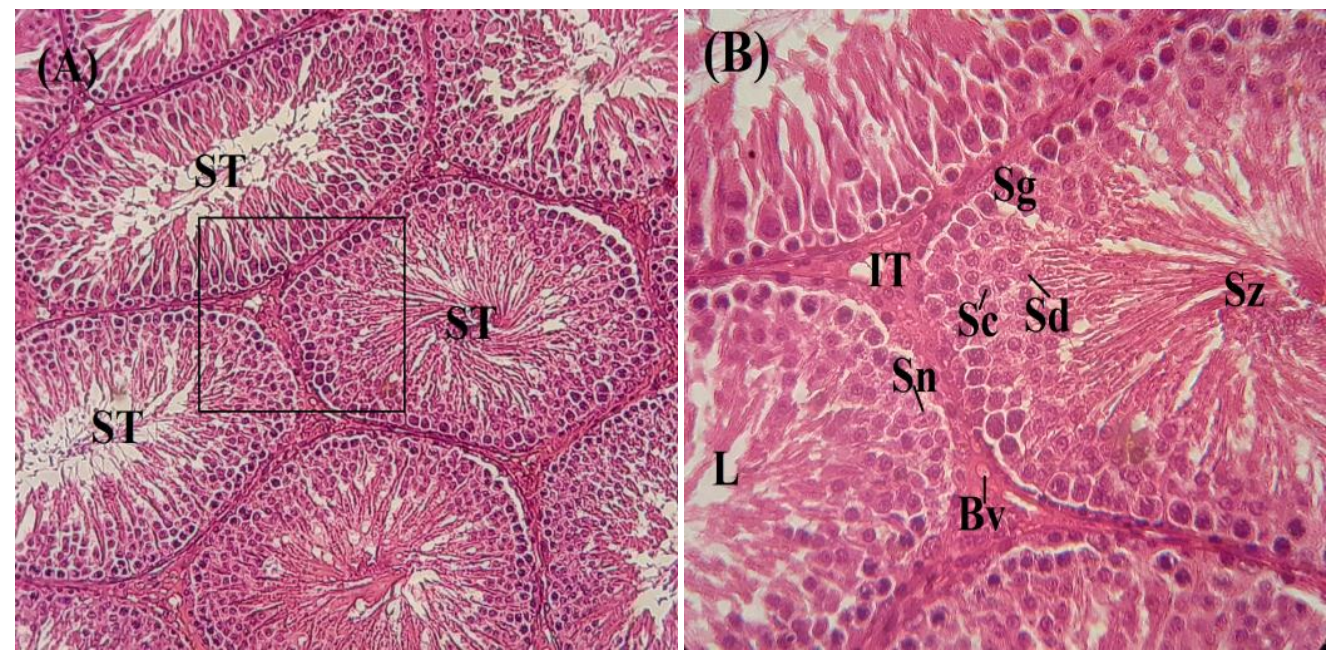

Figure 3: (A)-(B) Microscopic observation of Haematoxylin and eosin stained sections of the control rat testis. (A): Normal architecture and seminiferous tubes filled with sperm (ST) $\times 10$. (B): Higher magnification $(\times 40)$ of the inbox of (A) showing the normal progression of spermatogenesis from spermatogonia (Sg) to spermatozoa (Sz) via spermatocytes (Sc) and spermatids (Sd). Interstitial tissue (IT) formed by Leydig cells and blood vessels (Bv). The Sertoli cell nucleus (Sn) and the lumen of the seminiferous tube (L).
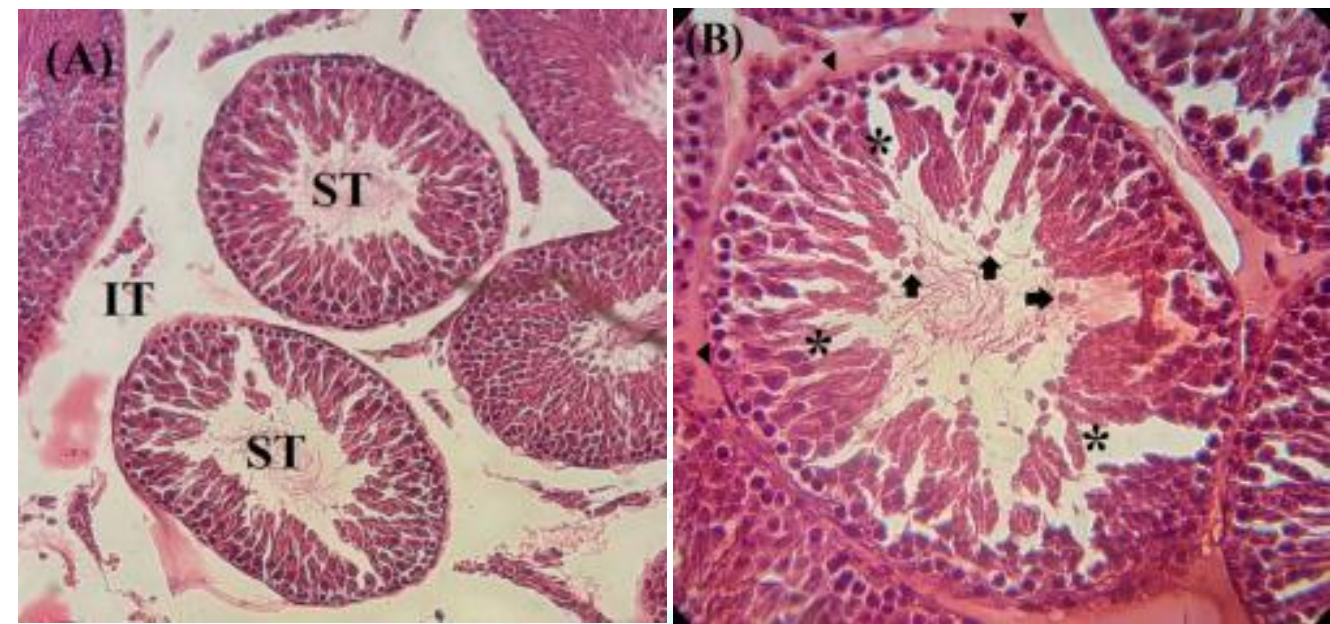

Figure 4: (A)-(B) Microscopic observation of Haematoxylin and eosin stained sections of $\mathrm{AlCl}_{3}$-exposed rat testis. (A): Showing a lack of Leydig cells with a large interstitial space (IT) and seminiferous tubules with sperm depletion (ST) (×10). (B): Showing disorganization of germinal epithelium (asterisks), lack of Leydig cells, and degeneration of interstitial tissue (arrowheads) with some exfoliated cells in the lumen (arrows) $(\times 40)$.

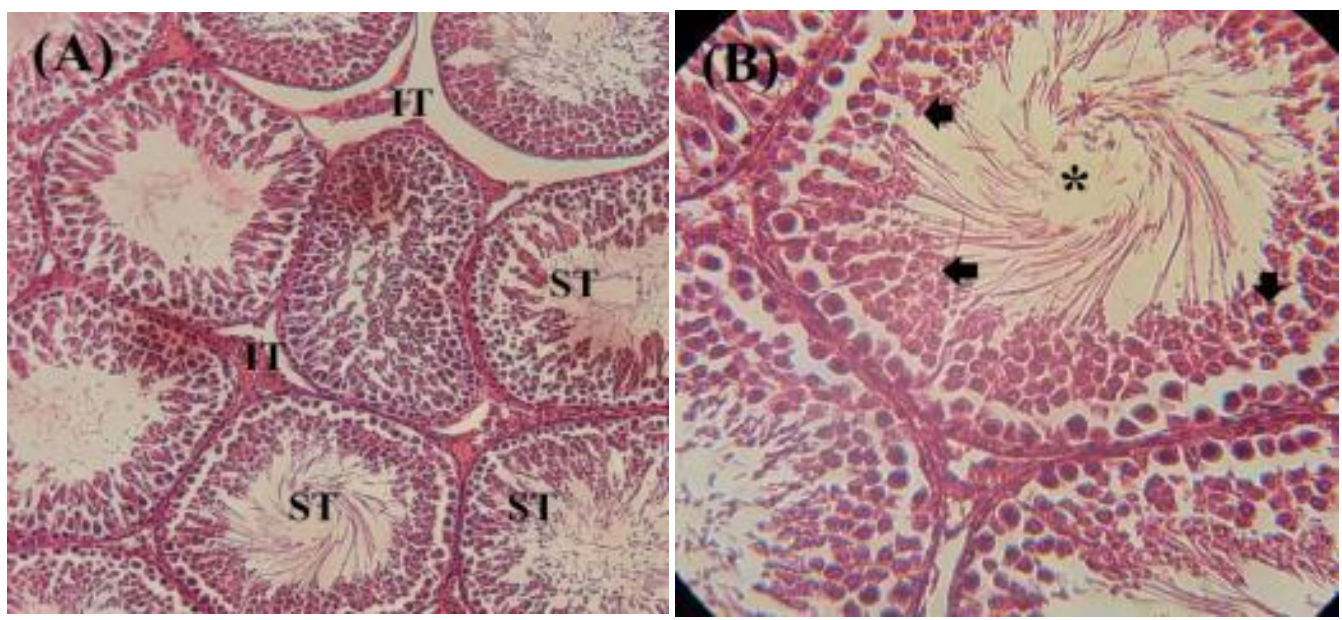

Figure 5: (A)-(B) Microscopic observation of Haematoxylin and eosin stained sections of both Aluminum and Curcuma longa treated rat testis $\left(\mathrm{AlCl}_{3}-\mathrm{CE}\right)$. (A): showing regeneration of the majority of seminiferous tubules (ST) and interstitial cells and reduction of interstitial space (IT) $(\times 10)$. (B): showing a good development of the spermatogenesis (arrows) and lumens of seminiferous tubes filled with sperm (asterisk) $(\times 40)$. 


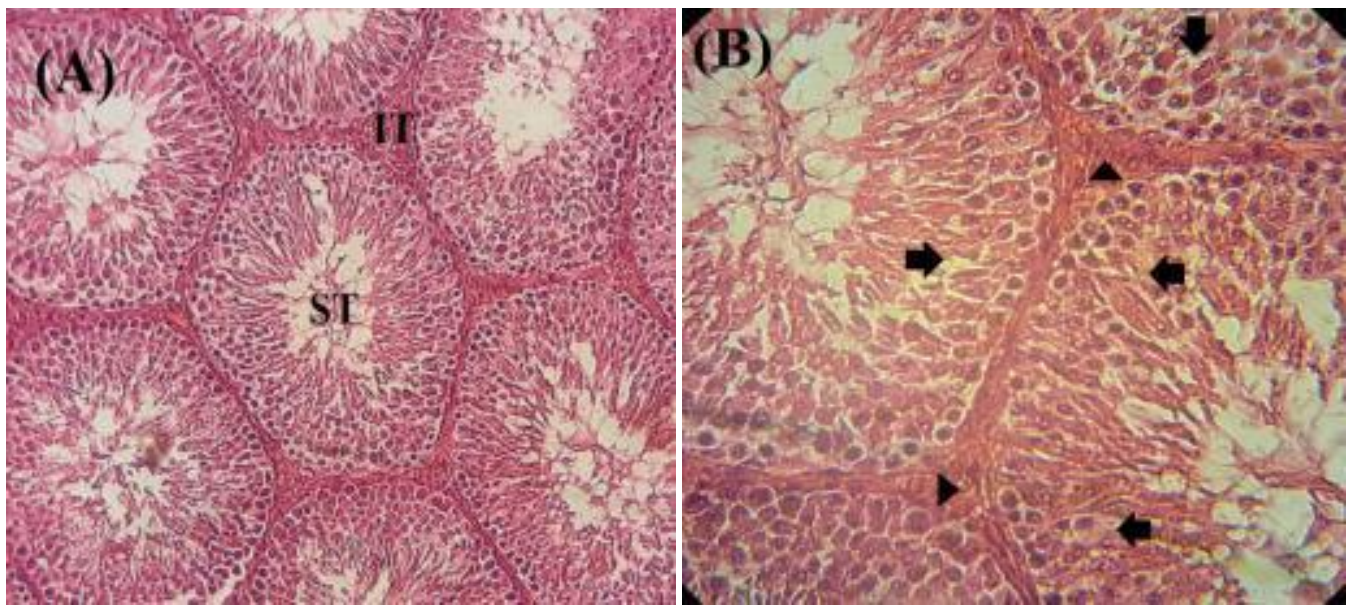

Figure 6: (A)-(B) Microscopic observation of Haematoxylin and eosin stained sections of only Curcuma longa treated rat testis (CE). (A): Showing a normal architecture approaching the normal state as in controls, with seminiferous tubules (ST) populated with spermatozoa, and interstitial tissue rich with Lydig cells with reduced interstitial space. (B): thick and well-structured germinal epithelium (arrows) and interstitial tissue rich with Lydig cells with reduced interstitial space (arrowheads) (×40).

\section{DISCUSSION}

The current study revealed that the administration of $\mathrm{AlCl}_{3}$ at the dose of $34 \mathrm{mg} / \mathrm{kg}$ BW to male rats during 4 weeks led to many reproductive system disorders including a decrease in sperm quality, hormonal disturbances, and induction of tissue oxidative stress. A significant decreased in sperm count, percent viability, and an increase in sperm abnormal morphology were observed. These results are in accordance with those obtained by Abdul-Rasoul, et al., (2009)28 who revealed that a daily administration of Aluminum chloride with two doses 40 and $80 \mathrm{mg} / \mathrm{kg}$ body weight induced a significant reduction in sperm concentration and percentage of live sperm, associated with a significant increase in the percentage of abnormal sperm. Another research conducted by Martinez et al., (2017) ${ }^{29}$ found that exposure to aluminum for 60 days at human dietary levels $(1.5,8.3$ and $100 \mathrm{mg} / \mathrm{kg}$ BW/day)affects the sperm quality in rats by decreasing sperm count, sperm motility, and sperm morphology, with an increase in oxidative stress and inflammation in reproductive organs. They found also that a low concentration of $\mathrm{Al}(3.35 \mu \mathrm{g} / \mathrm{g})$ in testes is sufficient to impair spermatogenesis. Moreover, Miska-Schramm et al., (2017) ${ }^{30}$ by using the Bank Vole (Myodesglareolus) as a rodent model indicate that $\mathrm{AlCl}_{3}$, at a dose of 3 and $200 \mathrm{mg} / \mathrm{l}$, impairs adult reproductive abilities by decreasing the quality and quantity of sperm cells and by causing morphologically abnormal development of the gonads. Also, Guoetal., (2005)12 indicated that aluminum exposure leads to an increase in nitric oxide (NO) products which were responsible for $\mathrm{Al}$-induced reproductive toxicity. Zhu et al., (2005) ${ }^{31}$ suggested that sub-chronic $\mathrm{AlCl}_{3}$ disorders the balance of trace element and decreases the spermatogenesis and testicular enzyme activities which have adverse effects on the testicular function in male rats. On the other hand, the results of the current study indicated that the administration of $\mathrm{AlCl}_{3}$ significantly decreased serum testosterone levels compared to control rats. These findings are consistent with those of Sun et al. (2011) ${ }^{32}$, who noticed a significant decrease in the levels of testosterone, follicle-stimulating hormone (FSH) and luteinizing hormone (LH) after 120 days of exposition to three doses $(64.18,128.36$ and 256.72 $\mathrm{mg} / \mathrm{kg}$ ) of aluminum and explain that $\mathrm{Al}$-exposure interferes with androgen receptor expressions in testes. Another work indicated that $\mathrm{AlCl}_{3}$ caused a significant decrease of $\mathrm{FSH}, \mathrm{LH}$, and testosterone, and caused the development of oligospermia and exfoliated tubules in the testis ${ }^{33}$. Hadiet al., (2020) noticed a significant decrease in testosterone and LH hormones after 60 days of $\mathrm{AlCl}_{3}(20 \mathrm{mg} \mathrm{AlCl} 3 / \mathrm{kg}$ b.w.) administration. They indicate that aluminum harms the steroidogenesis by increasing the production of nitric oxide which might inhibit LH levels. Knowing that, testosterone hormone is released from the Leydig cells by stimulation of $\mathrm{LH}$, its reduction results in the decline of serum testosterone concentration. Moreover, our study showed that Al exposure caused an elevation in the MDA level compared to the other experimental groups. Our finding is confirmed by those of Akayet al., (2016) ${ }^{34}$ who concluded that subchronic exposure to $\mathrm{Al}(75 \mathrm{mg} / \mathrm{kg} /$ day during 30 days) lead to a significant decrease on antioxidant enzymes such as SOD and GPx, and a significant increase in MDA levels compared to control group. This imbalance between the antioxidant system and oxidants leads to oxidative stress which has a destructive effect on the testis. The work of Afolabi et al., $(2018)^{35}$ on Aluminum phosphide, indicated that oral administration of $\mathrm{Al}(1.15 \mathrm{mg} / \mathrm{kg})$ during 30 days resulted in a significant increase in testicular MDA and oxidized protein levels with a decrease in antioxidant enzymes such as SOD, CAT and GPx followed by a significant reduction in nonenzymatic antioxidants. While, the observation of histological sections of the $\mathrm{AlCl}_{3}$ exposed group shows the degeneration of the seminiferous tubules and depletion of sperm in the seminiferous lumen, with large interstitial spaces and lack of cells Lydig around basement membranes. These results are following those obtained by Moselhy et al., $(2012)^{23}$ who demonstrated after histopathological examination of rats testis exposed to a daily dose (34 $\mathrm{mg} / \mathrm{kg}$ ) of $\mathrm{AlCl}_{3}$ during 60 days, revealed degenerative changes in seminiferous tubules with necrosed spermatogenic cells. On the other hand, our result showed that the treatment with Curcuma longa aqueous extract at a dose of $200 \mathrm{mg} / \mathrm{kg}$ body weight concomitant with $\mathrm{AlCl}_{3}$ exposure, led to significant improvement of some semen parameters with a significant elevation of serum testosterone and a decrease in MDA level. Furthermore, Histologic analysis showed a significant regeneration of the majority of seminiferous tubules and interstitial cells, with a good development of the spermatogenesis indicated by lumens of seminiferous tubes filled with sperm. These findings are in agreement with those of Cheraghi et al., (2017) ${ }^{36}$ who concluded that curcumin, the major constituent of Curcuma longa, significantly reversed the 
adverse effects of $\mathrm{Al}$ on testis and sperm quality. and explained that curcumin exhibits protective effects against oxidative damage by decreasing the levels of free radicals, through its free radical scavenging activity, particularly against oxygen radicals, which inhibit sulfhydryl ( $\mathrm{SH}$ )-group oxidation. It inhibits nuclear factor kappa B (NF-kB) activity, cyclooxygenase-2 (COX-2), and mitogen-activated protein kinase (MAPK) expression, while it modulates the release of several cytokines and testicular enzyme activities, mRNA expression of $17 \beta$-hydroxysteroid dehydrogenases (17 $\beta$ HSD). Besides, Belhan et al., (2017) finding confirmed the protective effect of curcumin and indicated that low dose curcumin $(10 \mathrm{mg} / \mathrm{kg})$ significantly increased sperm motility and concentration, and decreased abnormal sperm percentage with a significant suppressing of the lipid profile and an increase in testosterone levels. Furthermore, to assess the protective effect of curcumin on lead acetateinduced $(50 \mathrm{mg} / \mathrm{kg} \mathrm{BW})$ reprotoxicity, Sudjarwo et al., $(2017)^{37}$ found that daily oral administration of curcumin at three doses $(100,200$ and $400 \mathrm{mg} / \mathrm{kg})$ during 40 days to rats significantly improved the histopathological structure of testis, increased the sperm count, motility, viability, and also significantly increased the SOD, GPx, and decreased MDA in the testis of lead acetate-treated rats. They concluded that co-administration of curcumin at a dose of $400 \mathrm{mg} / \mathrm{kg}$ reduced the effects of lead acetate-induced testicular toxicity, possibly by inhibiting the free radical mediated process. In addition to the protective effect of $C$. longa on male reproductive function, a study also shows that the ethanolic extract of $C$. longa (100 mg/kg BW) successfully prevents female albino Wistar rats against bisphenol Ainducing reproductive toxicity ${ }^{38}$. Another study indicates also that Curcuma longa does not only possess a non-toxic effect but has cytoprotective effects on the histoarchitecture of the testes in diabetic rats ${ }^{39}$. By studying the effects of different doses of curcumin 25, 50, and $100 \mathrm{mg} / \mathrm{kg}$ during 14 days on reproductive organ weight index, testicular histopathology and apoptosis in a mouse aging model. Taba et al., (2019) 40 indicated that Curcumin supplementation (2 weeks, $100 \mathrm{mg} / \mathrm{kg}$ ) induced improvement in biochemical markers and sperm parameters as well as reduction of apoptosis in testicular tissue.

\section{CONCLUSION}

The current study demonstrated that Curcuma longa aqueous extract had a remarkable protective effect against $\mathrm{AlCl}_{3}$ reproductive toxicity and its mechanism is related, at least in part, to its high free radical scavenging and antioxidant activity. Further works are necessary to isolate bioactive compounds and elucidate the mechanism involved in the reprotective activity of this plant.

\section{CONFLICT OF INTEREST}

The authors declare that they have no conflict of interest.

\section{REFERENCES}

1. Mestaghanimi, H., et al., Effects of aluminium chloride on some essential elements in pregnant rats and their offspring. Revue Marocaine des Sciences Agronomiques et Vétérinaires, 2002; 22(4):227-234.

2. Abbasali, K., T. Zhila, and N. Farshad, Developmental toxicity of Aluminum from high doses of AlCl3 in mice. J. Applied Res., 2005; 5:575-579.

3. Mestaghanmi, H., S. El-Amrani, and R. Saile, Effects of aluminium chloride administration during gestation in rat. Stal, 2002; 27:7381.

4. Mahieu, S., et al., Alterations of the renal function and oxidative stress in renal tissue from rats chronically treated with aluminium during the initial phase of hepatic regeneration. Journal of inorganic biochemistry, 2005; 99(9):1858-1864.
5. Klöppel, H., A. Fliedner, and W. Kördel, Behaviour and ecotoxicology of aluminium in soil and water-Review of the scientific literature. Chemosphere, 1997; 35(1-2):353-363.

6. Buraimoh, A.A., et al., Histological study of the effects of aluminium chloride exposure on the testis of wistar rats. American International Journal of Contemporary Research, 2012; 2(5):114-122.

7. Kutlubay, R., et al., Vitamin E protection from testicular damage caused by intraperitoneal aluminium. International Journal of Toxicology, 2007; 26(4):297-306.

8. Yousef, M.I., A.M. El-Morsy, and M.S. Hassan, Aluminium-induced deterioration in reproductive performance and seminal plasma biochemistry of male rabbits: protective role of ascorbic acid. Toxicology, 2005; 215(1-2):97-107.

9. Yousef, M.I., et al., An in vitro study on reproductive toxicity of aluminium chloride on rabbit sperm: the protective role of some antioxidants. Toxicology, 2007; 239(3):213-223.

10. Yousef, M.I. and A.F. Salama, Propolis protection from reproductive toxicity caused by aluminium chloride in male rats. Food and chemical toxicology, 2009; 47(6):1168-1175.

11. Shahraki, M., S. ZAHEDIASL, and A. Sarkaki, The effect of aluminum injection in lateral ventricle on sex hormones in male rat. 2004.

12. Guo, C.-H., et al., Aluminum-induced suppression of testosterone through nitric oxide production in male mice. Environmental toxicology and pharmacology, 2005; 19(1):33-40.

13. Chinoy, N., R. Momin, and D. Jhala, Fluoride and aluminium induced toxicity in mice epididymis and its mitigation by vitamin C. Fluoride, 2005; 38(2):115-121.

14. Chinoy, N., H. Sorathia, and D. Jhala, Fluoride+ aluminium induced toxicity in mice testis with giant cells and its reversal by vitamin C. Fluoride, 2005; 38(2):109-114.

15. Boudou, F., et al., Ameliorative effects of Syzygium aromaticum essential oil on fertility in male rats exposed to manganese. Advances in sexual medicine, 2013. 2013.

16. Bagad, A.S., et al., Comparative evaluation of anti-inflammatory activity of curcuminoids, turmerones, and aqueous extract of Curcuma longa. Advances in pharmacological sciences, 2013. 2013.

17. Ramirez-Tortosa, M., et al., Oral administration of a turmeric extract inhibits LDL oxidation and has hypocholesterolemic effects in rabbits with experimental atherosclerosis. Atherosclerosis, 1999; 147(2):371-378.

18. Patil, M., et al., Extraction, isolation and evaluation of antiinflammatory activity of Curcuminoids from Curcuma longa. International Journal of Chemical Sciences and Applications, 2011; 2(3):172-174.

19. Devasagayam, T.P., J.P. Kamat, and N. Sreejayan, Antioxidant action of curcumin. Micronutrients and health: molecular biological mechanisms, 2001; 42-59.

20. Slemmer, J.E., et al., Antioxidants and free radical scavengers for the treatment of stroke, traumatic brain injury and aging. Current medicinal chemistry, 2008; 15(4):404-414.

21. Joe, B. and B. Lokesh, Role of capsaicin, curcumin and dietary $n-$ 3 fatty acids in lowering the generation of reactive oxygen species in rat peritoneal macrophages. Biochimica et Biophysica Acta (BBA)-Molecular Cell Research, 1994; 1224(2):255-263.

22. Serairi-Beji, R., et al., Antioxidant and hepatoprotective effects of Asparagus albus leaves in carbon tetrachloride-induced liver injury rats. Journal of Food Biochemistry, 2018; 42(1):e12433.

23. Moselhy, W., et al., Role of ginger against the reproductive toxicity of aluminium chloride in albino male rats. Reproduction in domestic animals, 2012; 47(2):335-343.

24. Govind, P., Active principles and median lethal dose of Curcuma longa Linn. Internafional Research Journal of Pharmacy, 2011; 2 (5):239.

25. Kim, E.-J., et al., An improved dehydroepiandrosterone-induced rat model of polycystic ovary syndrome (PCOS): Post-pubertal improve PCOS'S features. Frontiers in Endocrinology, 2018; 9:735.

26. Azad, F., et al., Antioxidant and anti-apoptotic effects of royal jelly against nicotine-induced testicular injury in mice. Environmental toxicology, 2019; 34(6):708-718.

27. Wang, Y., Epididymal sperm count. Current protocols in toxicology, 2002; 14(1):16.6.1-16.6. 5.

28. Abdul-Rasoul, E.M., N.H. Hassan, and K.H. Al-Mallah, Effect of aluminium chloride on sexual efficiency in adult male rats. JOURNAL OF EDUCATION AND SCIENCE, 2009; 22(4):27-44. 
29. Martinez, C.S., et al., Aluminum exposure for 60 days at human dietary levels impairs spermatogenesis and sperm quality in rats. Reproductive Toxicology, 2017; 73:128-141.

30. Miska-Schramm, A., J. Kapusta, and M. Kruczek, The effect of aluminum exposure on reproductive ability in the bank vole (Myodes glareolus). Biological trace element research, 2017; 177(1):97-106.

31. Zhu, Y., et al., Effects of sub-chronic aluminum chloride on spermatogenesis and testicular enzymatic activity in male rats. Life sciences, 2014; 102(1):36-40.

32. Sun, H., et al., Effects of aluminum exposure on serum sex hormones and androgen receptor expression in male rats. Biological trace element research, 2011; 144(1-3):1050-1058.

33. Al-Eisa, R. and $\mathrm{H}$. Al-Nahari, The attenuating effect of royal jelly on hormonal parameters in aluminum chloride (AlCl3) intoxicated rats. International Journal of Pharmaceutical Research \& Allied Sciences, 2017; 6(2).

34. Akay, C., et al., Oxidative effects of aluminum on testes and erythrocytes in rats. Trace Elements and Electrolytes, 2016; 33(4):155.

35. Afolabi, O.K., et al., Aluminium phosphide-induced testicular toxicity through oxidative stress in Wistar rats: Ameliorative role of hesperidin. Toxicology Research and Application, 2018; 2:2397847318812794.

36. Cheraghi, E., et al., Aluminium-induced oxidative stress, apoptosis and alterations in testicular tissue and sperm quality in Wistar rats: ameliorative effects of curcumin. International journal of fertility \& sterility, 2017; 11(3):166.

37. Sudjarwo, S.A. and K. Giftania Wardani Sudjarwo, Protective effect of curcumin on lead acetate-induced testicular toxicity in Wistar rats. Research in Pharmaceutical Sciences, 2017; 12(5):381.

38. BENALIA, A., et al., The Protective Effect of Curcuma longa (L.) against Bisphenol A-Induced Reproductive Toxicity in Adult Female Albino Wistar Rats. Journal of Biochemistry International, 2017; 63-72.

39. Olanrewaju, A., et al., Testicular cytoprotective activities of Curcuma longa in STZ-induced diabetic adult male wistar rats. Anatomy Journal of Africa, 2017; 6(1):905-913.

40. Taba, M.Y., et al., Effects of different doses of curcumin on testicular histopathology, apoptosis, and reproductive organs weight index in mice d-galactose-induced aging model. Comparative Clinical Pathology, 2019; 28(4):997-1002. 